\title{
Analyzing the formation of normal and abnormal $O$ waves in thoracic impedance graph using the impedance change components for aorta, blood vessels in lung and ventricles
}

\author{
Nan-Zhen Kuang ${ }^{1 *}$, Qiu-Jin Xiao ${ }^{2 *}$, Bai-Qing $\mathrm{He}^{3}$, Jing-Juan $\mathrm{Fu}^{3}$, Ming-Xing Kuang ${ }^{1}$ \\ ${ }^{1}$ Department of Basic Medicine, Medical College of Nanchang University, Jiangxi Nanchang, China \\ ${ }^{2}$ Department of Special Diagnosis, Great Wall Hospital of Nanchang University, Jiangxi Nanchang, China \\ ${ }^{3}$ Department of Electronic Engineering, Nanchang Institute of Technology, Nanchang, China
}

\begin{abstract}
Background: Many measurements of thoracic impedance graph show that the small C wave and big $O$ wave appear often for patients with cardiac insufficiency, and the $\mathrm{O} / \mathrm{C}$ ratio is bigger. And for the normal body, especially a younger one, the bigger $O$ wave may also appear. But since the amplitude of the $C$ wave of a normal body is bigger, the $O / C$ ratio is smaller. The aim of the present paper is to investigate the formation mechanism of the normal and abnormal $O$ waves in thoracic impedance graph.
\end{abstract}

Methods and Results: The thoracic mixed impedance changes are measured with 6 leads consisting of 15 electrodes. The impedance change components for the aorta (AO), blood vessel in left lung $(P L)$, blood vessel in right lung $(P R)$, left ventricle $(L V)$ and right ventricle $(R V)$ are separated from thoracic mixed impedance changes by means of establishing and solving the thoracic impedance equations. The amplitudes of the $O$ and $C$ waves of various impedance change components are measured for 50 normal healthy adults and 34 patients with cardiac insufficiency. The formation mechanism of normal and abnormal $O$ waves in thoracic impedance graph is analyzed using the superposition of the $O$ waves of the above impedance change components. Detection subjects are 50 healthy adults and 34 hospital patients with cardiac insufficiency. (1) Thoracic impedance graph: The $\mathrm{O} / \mathrm{C}$ ratios of the normal group are significantly smaller than that of the abnormal group, $p<0.001$. The $O$ wave of first lead $\left(E_{1}-E_{1}{ }^{\prime}\right)$ is significantly bigger than that of leads 4 and $5\left(E_{4}-E_{4}{ }^{\prime}\right.$ and $\left.E_{5}-E_{5}{ }^{\prime}\right)$ in the normal group, $p<0.001$. (2) The impedance change component: The $O$ waves of the AO, PL, and PR are significantly smaller than that of the $L V$ and $R V$ in the normal group, $p<0.001$. The $O$ wave and $\mathrm{O} / \mathrm{C}$ of the $A O, P L$ and PR of normal group are significantly smaller than that of the abnormal group, $p<0.001$.

Conclusions: The $O$ wave of the thoracic impedance graph is formed due to the superposition of the $O$ waves of the impedance change components for the aorta, blood vessels in lung and ventricles. (Cardiol J 2014; 21, 2: 176-182)

Key words: thoracic impedance graph, impedance change component, $\mathrm{O}$ wave, superposition, formation

Address for correspondence: Dr Qiu-Jin Xiao, Department of Special Diagnosis, Great Wall Hospital of Nanchang University, Jiangxi Nanchang 330002, China, e-mail: fall94@qq.com

Received: 08.04.2013 Accepted: 18.12.2013

*These authors contributed equally to this work and should be considered co-first authors. 


\section{Introduction}

The thoracic impedance graph is an impedance change curve measured on the chest surface. Since its waveform graph includes much information concerning the physiological activities and pathological changes of the heart and blood vessels, it has been used to determine the cardiac functions and to monitor the hemodynamic changes in patients in clinic extensively [1-7]. The clinic detections show that there is a positive or negative $\mathrm{O}$ wave in the thoracic impedance differential graph after second cardiac sound [8-10], as shown in Figure 1. The bigger $\mathrm{O}$ wave appears often and the $\mathrm{O} / \mathrm{C}$ ratio of the amplitude of the $\mathrm{O}$ wave to that of the $\mathrm{C}$ wave increases for the patients with cardiac insufficiency $[8,11,12]$. And for normal body, especially a younger one, the bigger $\mathrm{O}$ wave may also appear at times. But since the amplitude of the $\mathrm{C}$ wave of the normal body is bigger, the $\mathrm{O} / \mathrm{C}$ ratio is smaller. How to form these abnormal and normal $\mathrm{O}$ waves?

Many studies have proved that thoracic impedance graph measured with Kubicek's method (or

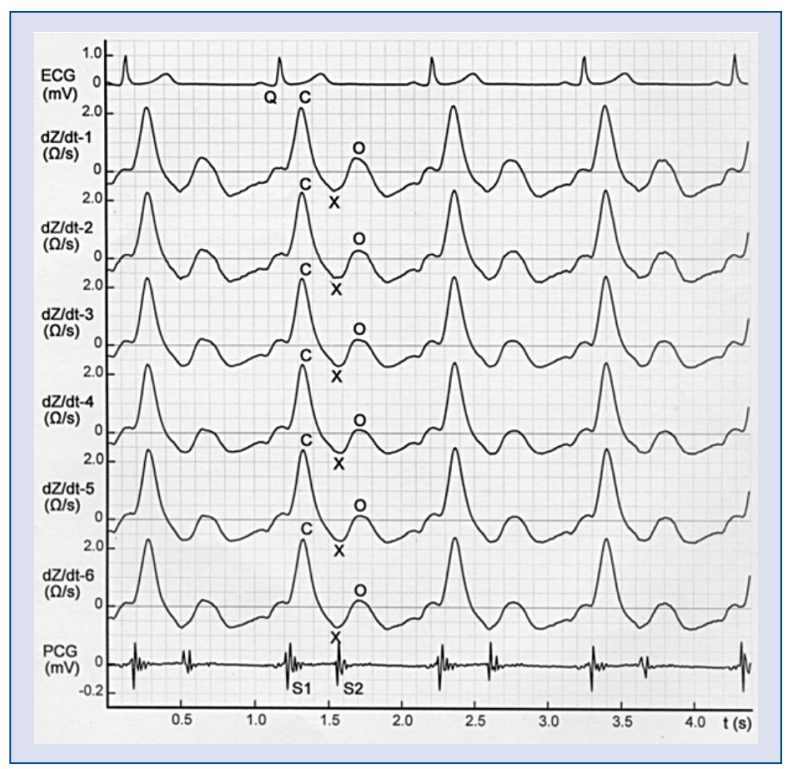

Figure 1. Differential graphs of the thoracic mixed impedance changes. Lines $2,3,4,5,6$, and 7 are the thoracic mixed impedance differential graphs (dZ/dt-1, dZ/dt-2, $d Z / d t-3, d Z / d t-4, d Z / d t-5$, and dZ/dt-6) of 6 leads $\left(E_{1}-E_{1}{ }^{\prime}\right.$, $E_{2}-E_{2}{ }^{\prime}, E_{3}-E_{3}{ }^{\prime}, E_{4}-E_{4}{ }^{\prime}, E_{5}-E_{5}{ }^{\prime}$, and $\left.E_{6}-E_{6}{ }^{\prime}\right)$, respectively. Symbols $\mathrm{C}, \mathrm{X}$ and $\mathrm{O}$ denote the $\mathrm{C}$ wave, $\mathrm{X}$ wave and $\mathrm{O}$ wave, respectively. Lines 1 and 8 are the electrocardiography (ECG) and phonocardiagram (PCG), respectively. Q symbol denotes the initial point of the ECG's Q wave, and S1 and S2 denote the first and second cardiac sounds, respectively. $\Omega / s$ is the unit of the impedance differential graphs, and $\mathrm{mV}$ is that of ECG and PCG.
Sramek's method) is a kind of mixed impedance signal [13-16] which mainly evokes from the volume changes of the aorta (AO), blood vessels in lung and ventricles. Obviously, the measurement results obtained with this mixed signal include not only the left heart effects, but also the right heart effects. This method lacks the uniqueness in evaluating the cardiac function of the left ventricle (LV). For this reason, we have separated the impedance change components for the AO, blood vessel in left lung (PL), blood vessel in right lung $(\mathrm{PR}), \mathrm{LV}$ and right ventricle (RV) from the mixed impedance changes measured on the chest surface $[17,18]$. There is also an $\mathrm{O}$ wave in differential graphs of these impedance change components, as shown in Figure 2. In these graphs, the $\mathrm{O}$ waves of the vascular components (AO, PL, and PR) are positive or negative, and the amplitude is smaller. While the $\mathrm{O}$ waves of the ventricle components ( $\mathrm{LV}$ and RV) are positive, the amplitude is bigger [18].

Now that the $\mathrm{O}$ waves of various impedance change components (AO, PL, PR, LV, and RV) can be obtained from the mixed impedance changes measured on the chest surface through separation, the $\mathrm{O}$ wave of the thoracic impedance graph can be

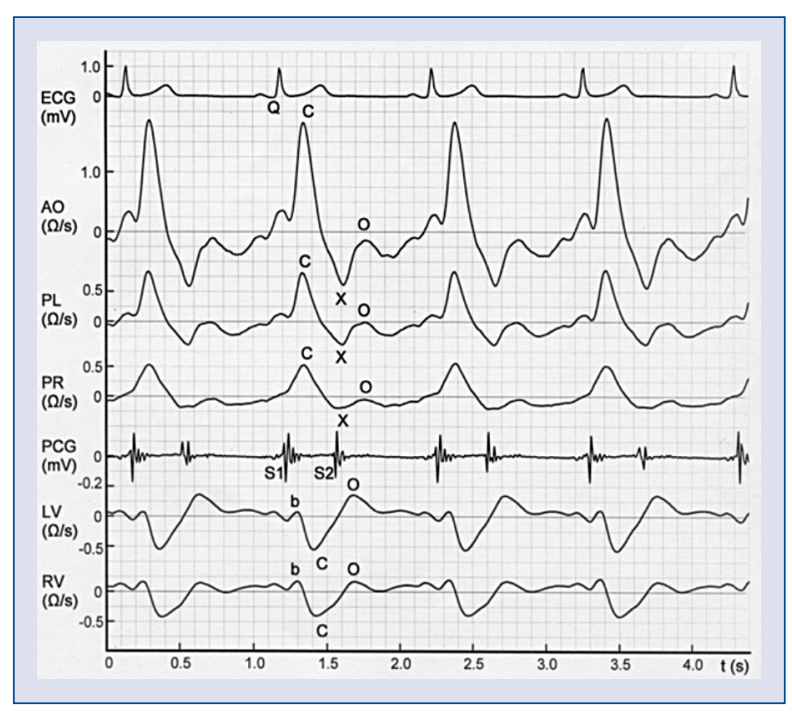

Figure 2. Differential graphs of impedance change components. Lines 2, 3, 4, 6, and 7 are the differential graphs of the aorta $(A O)$, blood vessel in left lung $(P L)$, blood vessel in right lung (PR), left ventricle (LV) and right ventricle $(R V)$, respectively. Symbol $C$ is the peak point of the $C$ wave in the systolic phase. $X$ is the negative peak point of the $X$ wave of the $A O, P L$, and PR. $b$ is the peak point of the $b$ wave of the LV and RV in the initial systolic stage. $\mathrm{O}$ is the peak point of the $\mathrm{O}$ wave in the initial diastolic phase. The meanings of $\mathrm{Q}, \mathrm{S} 1, \mathrm{~S} 2, \Omega / \mathrm{s}$ and $\mathrm{mV}$ symbols are the same as in Figure 2. 
also gained through composition (or superposition) of the $\mathrm{O}$ waves of the various components. The formation mechanism of the normal and abnormal $\mathrm{O}$ waves in the thoracic impedance graph is analyzed according to the above thinking of the inverse operation in this paper. And the amplitudes of the $\mathrm{O}$ and $\mathrm{C}$ waves for 50 normal healthy adults and 34 patients with cardiac insufficiency are measured.

The study was approved by the local bioethical committee and all patients gave their informed consent.

\section{Methods}

\section{Measurement of thoracic mixed impedance changes}

The thoracic mixed impedance changes and basic impedances are measured with 6 leads consisting of 15 electrodes [18]. The electrode positions are shown in Figure 3. In addition, the electrodes for sensing the electrocardiography (ECG) are attached to the right upper arm and to the outside of left and right lower legs. The transducer for sensing the phonocardiogram (PCG) is placed at the position of cardiac apex on chest surface. The measurement instrument used in this study was developed by the research group [18]. The body height, body weight, chest circumference, chest breadth between left and right sides of thorax,

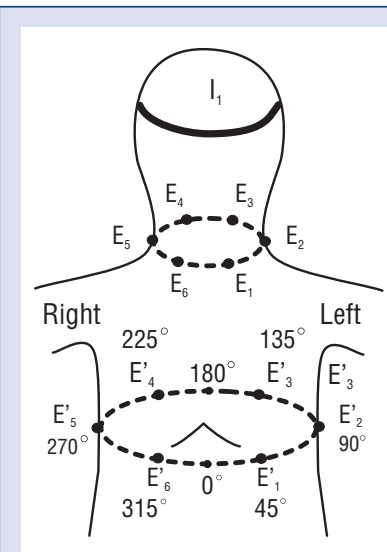

(a)

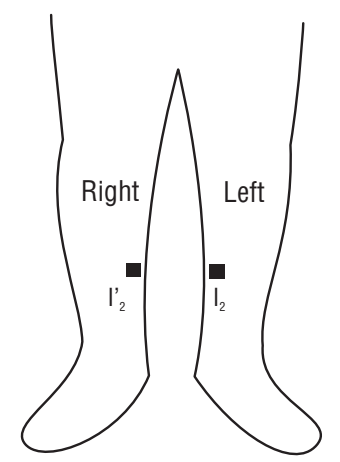

(b)
Figure 3. Arrangement of the impedance detection electrodes. $I_{1}, I_{2}$, and $I_{2}{ }^{\prime}$ are 3 silvered copper current electrodes. 12 black circular dots in Figure 1 are the disposable $\mathrm{Ag} / \mathrm{AgCl}$ voltage electrodes, where $\mathrm{E}_{1}, \mathrm{E}_{2}$, $E_{3}, E_{4}, E_{5}$, and $E_{6}$ are the neck voltage electrodes applied to the neck root and $\mathrm{E}_{1}{ }^{\prime}, \mathrm{E}_{2}{ }^{\prime}, \mathrm{E}_{3}{ }^{\prime}, \mathrm{E}_{4}{ }^{\prime}, \mathrm{E}_{5}{ }^{\prime}$, and $\mathrm{E}_{6}{ }^{\prime}$ are the chest voltage electrodes applied to the chest surface at the xiphoid level. blood pressure, as well as the name, sex and age are entered into the computer prior to the measurement. The chest circumference and chest breadth are measured on the chest surface at the xiphoid level. The supine position of the body is adopted for the measurement. The subject is asked to hold his/her breath for the duration of the measurement. The thoracic mixed impedance changes $\left(\Delta Z_{\mathrm{s} 1}, \Delta Z_{\mathrm{s} 2}\right.$, $\Delta Z_{\mathrm{s} 3}, \Delta Z_{\mathrm{s} 4}, \Delta Z_{\mathrm{s} 5}$, and $\left.\Delta Z_{\mathrm{s} 6}\right)$ and basal impedances $\left(Z_{0 \mathrm{~s} 1}, Z_{0 \mathrm{~s} 2}, Z_{0 \mathrm{~s} 3}, Z_{0 \mathrm{~s} 4}, Z_{0 \mathrm{~s} 5}\right.$, and $\left.Z_{0 \mathrm{~s} 6}\right)$ of 6 leads, as well as ECG and PCG are recorded by computer, simultaneously. Six differential graphs of the thoracic mixed impedance changes can be obtained through the software differentiation and plotting, respectively, as shown in Figure 1 (2-7 lines). Then the amplitudes of the $\mathrm{O}$ wave and $\mathrm{C}$ wave of various leads are measured, respectively. And the $\mathrm{O} / \mathrm{C}$ ratio of the amplitude of the $\mathrm{O}$ wave to that of the $\mathrm{C}$ wave for various leads is calculated, respectively.

\section{Impedance change components for the} aorta, blood vessels in lung and ventricles

The data of the thoracic mixed impedance changes $\left(\Delta Z_{\text {s1 } 1}\right.$ to $\left.\Delta Z_{\text {s6 }}\right)$ measured above are orderly substituted into the thoracic impedance equations according to the mathematical method in reference number [20]. The impedance change components for the AO, PL, PR, LV and RV are separated from 6 thoracic mixed impedance changes through solving the thoracic impedance equations. Figure 2 shows the differential graphs of various impedance change components (AO, PL, PR, LV, and RV), corresponding to Figure 1. Then, the amplitudes of the $\mathrm{O}$ and $\mathrm{C}$ waves of various components are measured, respectively. Next, the $\mathrm{O} / \mathrm{C}$ ratio of the amplitude of the $\mathrm{O}$ wave to that of the $\mathrm{C}$ wave for the AO, PL, and PR are calculated, respectively.

\section{Detection subjects}

The detection subjects are divided into the normal and abnormal groups. The normal group is 50 healthy adults with normal cardiac function, including 25 males and 25 females. The age is $45-$ -74 years with an average of $58.4 \pm 7.2$ years. The heart rate is in the range of $60-901 / \mathrm{min}$ with mean of $71.2 \pm 9.21 / \mathrm{min}$. The systolic pressure is below $140 \mathrm{~mm} \mathrm{Hg}$, and the diastolic pressure is in the range of $65-89 \mathrm{~mm} \mathrm{Hg}$. The left ventricular ejection fraction (LVEF) is bigger than $50 \%$, and an average is $61.6 \pm 6.7 \%$ (LVEF is measured using 2-dimensional echocardiography, Simpson method). Their bodies are neither unduly obese, nor unduly emaciated. The mean of the body mass index is $24.1 \pm 3.1 \mathrm{~kg} / \mathrm{m}^{2}$. 
Table 1. The measurement results of the $\mathrm{C}$ wave, $\mathrm{O}$ wave and $\mathrm{O} / \mathrm{C}$ ratio for the thoracic impedance differential graphs of 6 leads.

\begin{tabular}{lccccc}
\hline Leads & Item & Normal groups $(\mathbf{n}=50)$ & Abnormal group $(\mathbf{n}=\mathbf{3 4})$ & $\mathbf{t}$ & $\mathbf{p}$ \\
\hline 1. $\mathrm{E}_{1}-\mathrm{E}_{1}{ }^{\prime}$ & $\mathrm{C}(\Omega / \mathrm{s})$ & $1.924 \pm 0.610$ & $0.897 \pm 0.401$ & 8.62 & $<0.001$ \\
& $\mathrm{O}(\Omega / \mathrm{s})$ & $0.162 \pm 0.235$ & $0.224 \pm 0.234$ & 1.19 & $>0.2$ \\
& $\mathrm{O} / \mathrm{C}$ & $0.086 \pm 0.125$ & $0.294 \pm 0.328$ & 4.08 & $<0.001$ \\
2. $\mathrm{E}_{2}-\mathrm{E}_{2}{ }^{\prime}$ & $\mathrm{C}(\Omega / \mathrm{s})$ & $1.859 \pm 0.562$ & $0.845 \pm 0.356$ & 9.64 & $<0.001$ \\
& $\mathrm{O}(\Omega / \mathrm{s})$ & $0.085 \pm 0.206$ & $0.198 \pm 0.203$ & 2.42 & $<0.05$ \\
& $\mathrm{O} / \mathrm{C}$ & $0.043 \pm 0.107$ & $0.283 \pm 0.330$ & 4.80 & $<0.001$ \\
3. $\mathrm{E}_{3}-\mathrm{E}_{3}{ }^{\prime}$ & $\mathrm{C}(\Omega / \mathrm{s})$ & $1.790 \pm 0.547$ & $0.801 \pm 0.336$ & 9.40 & $<0.001$ \\
& $\mathrm{O}(\Omega / \mathrm{s})$ & $0.023 \pm 0.180$ & $0.138 \pm 0.176$ & 2.90 & $<0.01$ \\
& $\mathrm{O} / \mathrm{C}$ & $0.010 \pm 0.101$ & $0.224 \pm 0.298$ & 4.71 & $<0.001$ \\
$4 . \mathrm{E}_{4}-\mathrm{E}_{4}{ }^{\prime}$ & $\mathrm{C}(\Omega / \mathrm{s})$ & $1.849 \pm 0.548$ & $0.854 \pm 0.377$ & 9.20 & $<0.001$ \\
& $\mathrm{O}(\Omega / \mathrm{s})$ & $-0.033 \pm 0.162$ & $0.119 \pm 0.191$ & 3.92 & $<0.001$ \\
& $\mathrm{O} / \mathrm{C}$ & $-0.020 \pm 0.090$ & $0.207 \pm 0.323$ & 4.72 & $<0.001$ \\
$5 . \mathrm{E}_{5}-\mathrm{E}_{5}{ }^{\prime}$ & $\mathrm{C}(\Omega / \mathrm{s})$ & $1.886 \pm 0.587$ & $0.845 \pm 0.392$ & 9.05 & $<0.001$ \\
& $\mathrm{O}(\Omega / \mathrm{s})$ & $-0.031 \pm 0.169$ & $0.144 \pm 0.204$ & 4.28 & $<0.001$ \\
& $\mathrm{O} / \mathrm{C}$ & $-0.017 \pm 0.095$ & $0.254 \pm 0.364$ & 5.03 & $<0.001$ \\
$6 . \mathrm{E}_{6}-\mathrm{E}_{6}{ }^{\prime}$ & $\mathrm{C}(\Omega / \mathrm{s})$ & $1.888 \pm 0.568$ & $0.854 \pm 0.428$ & 9.04 & $<0.001$ \\
& $\mathrm{O}(\Omega / \mathrm{s})$ & $0.005 \pm 0.197$ & $0.181 \pm 0.224$ & 3.80 & $<0.001$ \\
& $\mathrm{O} / \mathrm{C}$ & $0.006 \pm 0.112$ & $0.325 \pm 0.442$ & 4.89 & $<0.001$ \\
\hline
\end{tabular}

Values in the table are mean $\pm S D$. Symbols $E_{1}-E_{1}{ }^{\prime}, E_{2}-E_{2}{ }^{\prime}, E_{3}-E_{3}{ }^{\prime}, E_{4}-E_{4}{ }^{\prime}, E_{5}-E_{5}{ }^{\prime}$, and $E_{6}-E_{6}{ }^{\prime}$ denote 6 leads on the chest surface, respectively. Symbols $\mathrm{C}, \mathrm{O}$ and $\mathrm{O} / \mathrm{C}$ denote the amplitude of the $\mathrm{C}$ wave, that of the $\mathrm{O}$ wave and the ratio of the amplitude of the $\mathrm{O}$ wave to that of the $\mathrm{C}$ wave for the corresponding lead, respectively. The unit of the amplitude of the $C$ and $O$ waves is $\Omega / s$, and $O / C$ has no dimension. $n$ symbol is the number of the subjects.

The abnormal group consists of 34 hospital patients with cardiac insufficiency, including 18 males and 16 females. The age is $48-78$ with an average is $60.6 \pm 8.0$ years. The LVEF of all patients is smaller than $43 \%$, and the mean is $33.6 \pm 6.7 \%$. The thoracic impedance graph and LVEF of the patients are measured prior to the therapy. There is no significant difference between the mean ages of normal and abnormal groups, $\mathrm{p}>0.15(\mathrm{t}=1.31)$.

\section{Statistical analysis}

Statistical analysis was performed using the statistical software SPSS12.0. The measurement results of the amplitude of the $\mathrm{C}$ and $\mathrm{O}$ waves, as well as the $\mathrm{O} / \mathrm{C}$ ratio are expressed as mean values \pm standard deviation. The difference level between two mean values for the same index of the normal and abnormal groups is evaluated using the student t-test. If the p-value is smaller than 0.05 , there is a significant difference between the two mean values.

\section{Results}

The amplitudes of the $\mathrm{C}$ and $\mathrm{O}$ waves, as well as the $\mathrm{O} / \mathrm{C}$ ratios are statistically calculated according to the normal and abnormal groups for the thoracic impedance differential graphs and for the differential graphs of the impedance change components, respectively. The results are listed in Tables 1 and 2.

(1) The thoracic impedance graph: as shown in Table 1 , the amplitudes of the $\mathrm{C}$ waves of the normal group are bigger than those of the abnormal group, $\mathrm{p}<0.001$, while the amplitudes of the $\mathrm{O}$ waves of the normal group are smaller than those of the abnormal group, $\mathrm{p}<0.05$ (expect for first lead $\left.\mathrm{E}_{1}-\mathrm{E}_{1}{ }^{\prime}\right)$. The $\mathrm{O} / \mathrm{C}$ ratios of the abnormal group are bigger than those of the normal group, $\mathrm{p}<0.001$. The $O$ wave of first lead $\left(E_{1}-E_{1}^{\prime}\right)$ is bigger than those of 4 and 5 leads $\left(\mathrm{E}_{4}-\mathrm{E}_{4}{ }^{\prime}\right.$ and $\left.\mathrm{E}_{5}-\mathrm{E}_{5}{ }^{\prime}\right)$ in the normal group, $\mathrm{p}<0.001(\mathrm{t}>4.19)$.

(2) The impedance change components: as shown in Table 2 , the $\mathrm{O}$ waves of the vascular components (AO, PL, and PR) are smaller than those of the ventricle components ( $\mathrm{LV}$ and RV) in the normal group, $\mathrm{p}<0.001$. The $\mathrm{O}$ waves of the $\mathrm{LV}$ and RV of the normal group are bigger than those of the abnormal group, $\mathrm{p}<0.01$. The $\mathrm{O}$ waves and $\mathrm{O} / \mathrm{C}$ ratios of the $\mathrm{AO}, \mathrm{PL}$, and $\mathrm{PR}$ of the abnormal group are bigger than those of the normal group, $\mathrm{p}<0.001$. 
Table 2. The measurement results of the $\mathrm{C}$ wave, $\mathrm{O}$ wave and $\mathrm{O} / \mathrm{C}$ ratio for the differential graph of the separated impedance change components.

\begin{tabular}{lccccc}
\hline Component & Item & Normal groups $(\mathbf{n}=50)$ & Abnormal group $(\mathbf{n}=34)$ & $\mathbf{t}$ & $\mathbf{p}$ \\
\hline 1. $\mathrm{AO}$ & $\mathrm{C}(\Omega / \mathrm{s})$ & $1.416 \pm 0.350$ & $0.741 \pm 0.300$ & 9.18 & $<0.001$ \\
& $\mathrm{O}(\Omega / \mathrm{s})$ & $-0.053 \pm 0.172$ & $0.101 \pm 0.133$ & 4.40 & $<0.001$ \\
& $\mathrm{O} / \mathrm{C}$ & $-0.041 \pm 0.125$ & $0.157 \pm 0.213$ & 5.36 & $<0.001$ \\
2. PL & $\mathrm{C}(\Omega / \mathrm{s})$ & $0.700 \pm 0.210$ & $0.335 \pm 0.137$ & 8.91 & $<0.001$ \\
& $\mathrm{O}(\Omega / \mathrm{s})$ & $0.005 \pm 0.105$ & $0.097 \pm 0.072$ & 4.44 & $<0.001$ \\
& $\mathrm{O} / \mathrm{C}$ & $0.015 \pm 0.158$ & $0.384 \pm 0.446$ & 5.37 & $<0.001$ \\
3. PR & $\mathrm{C}(\Omega / \mathrm{s})$ & $0.515 \pm 0.156$ & $0.256 \pm 0.115$ & 8.27 & $<0.001$ \\
& $\mathrm{O}(\Omega / \mathrm{s})$ & $-0.040 \pm 0.101$ & $0.095 \pm 0.097$ & 6.11 & $<0.001$ \\
& $\mathrm{O} / \mathrm{C}$ & $-0.064 \pm 0.193$ & $0.493 \pm 0.547$ & 6.63 & $<0.001$ \\
4. LV & $\mathrm{C}(\Omega / \mathrm{s})$ & $-0.438 \pm 0.146$ & $-0.185 \pm 0.121$ & 8.34 & $<0.001$ \\
& $\mathrm{O}(\Omega / \mathrm{s})$ & $0.241 \pm 0.096$ & $0.130 \pm 0.090$ & 3.07 & $<0.01$ \\
$5 . \mathrm{RV}$ & $\mathrm{C}(\Omega / \mathrm{s})$ & $-0.379 \pm 0.149$ & $-0.182 \pm 0.113$ & 6.53 & $<0.001$ \\
& $\mathrm{O}(\Omega / \mathrm{s})$ & $0.172 \pm 0.073$ & $0.109 \pm 0.105$ & 3.25 & $<0.01$ \\
\hline
\end{tabular}

Values in the table are mean \pm SD. Symbols AO, PL, PR, LV and RV denote 5 impedance change components for the aorta, blood vessel in left lung, blood vessel in right lung, left ventricle and right ventricle, respectively. The meanings of $\mathrm{C}, \mathrm{O}, \mathrm{O} / \mathrm{C}$ and $\mathrm{n}$ symbols are the same as in Table 1.

\section{Discussion}

\section{Feasibility of the analyzed method in this paper}

As previously mentioned, the impedance change components for the AO, PL, PR, LV and RV are obtained from the mixed impedance changes measured on chest surface through the separation. The experiment results of 80 cases show that the main waveforms of the vascular components (AO, $\mathrm{PL}$, and PR) in the systolic phase are upward, while those of the ventricle components (LV and RV) are downward, and they are in opposite phase [18]. This corresponds with the cardiovascular active process that the volume of ventricles diminishes, while the volume of the blood vessels expands in the systolic phase. It is known from the physiology that the second cardiac sound (S2) arises and the volume of the ventricle is smallest when the semilunar valves of the aorta begin to close. In the waveform graph of the various impedance change components, the negative peak points of the LV and RV are in phase with the second cardiac sound (S2) basically [18]. This means that the time phase of the negative peak point of the LV and RV is in accordance with that of the ventricle volume in the smallest state. It is evident that the waveform graphs of the separated impedance change components (AO, PL, PR, LV, and RV) can reflect the physiological activity of the heart and blood vessels in thorax.

On the basis of the measurement principle of the electrical impedance graph, thoracic impedance change is measured by means of transforming it into the voltage change [17]. That is, the thoracic impedance change is expressed with voltage change in the measurement. This indicates that the superposition of the impedance changes is actually that of the corresponding voltage changes, and it corresponds to the electrical theory in the physics [19]. Thus, the method of analyzing the formation mechanism of the $\mathrm{O}$ wave of the thoracic impedance graph is feasible, using the superposition of the $\mathrm{O}$ waves of the above impedance change components in the present paper.

\section{Formation of the normal and abnormal $\mathrm{O}$ waves in thoracic impedance graph}

According to the superposition formula of the impedance changes [17], the thoracic impedance change measured between two voltage electrodes on the chest surface should be equal to the algebraic addition of the impedance changes caused by the aorta, blood vessels in lung and ventricles in same moment. Thus, the $\mathrm{O}$ wave in the thoracic impedance graph is formed due to the superposition of the $\mathrm{O}$ waves of the impedance change components for the aorta, blood vessels in lung and ventricles.

It is known from Table 2 that the $\mathrm{O}$ waves of the vascular components (AO, PL, and PR) of the normal body are positive or negative, and their amplitude is smaller. While the $\mathrm{O}$ waves of the ventricle components (LV and RV) are positive, their amplitude is bigger. Thus the $\mathrm{O}$ waves of the LV and RV are of main roles in the $\mathrm{O}$ wave of thoracic impedance graph of the normal body, while the AO, PL and PR are of minor roles. In 
this condition, the evident positive $\mathrm{O}$ wave could appear in thoracic impedance graph, even if there is no evident positive $\mathrm{O}$ wave in the AO, PL and PR, as shown in Figures 1 and 2.

In the condition of cardiac insufficiency, the $\mathrm{O}$ wave in the thoracic impedance graph is also formed due to the superposition of the $\mathrm{O}$ waves of the various impedance change components (AO, PL, PR, LV, and RV). But the amplitudes of the $\mathrm{O}$ waves of various components have changed this time. The $\mathrm{O}$ wave of the ventricle components ( $\mathrm{LV}$ and RV) of the abnormal group is smaller than that of the normal group (see Table 2), while the $\mathrm{O}$ waves of vascular components (AO, PL, and PR) are bigger than thoseof the normal group. The role of the O waves of the ventricle components in thoracic impedance graph is shrunken in this condition, while that of the vascular components is greatened. If the $\mathrm{O}$ wave of the vascular components is bigger than that of the ventricle components, the $\mathrm{O}$ wave of the vascular components plays the main role in the thoracic impedance graph and the $\mathrm{O} / \mathrm{C}$ ratio of the PL and PR is bigger.

The authors have proved that the impedance change caused by a single blood vessel on the chest surface is inversely proportional to the distance between the blood vessel and the line joining 2 detection electrodes [17]. That is, the bigger the distance from the blood vessel to the detection electrodes, the smaller the impedance change caused between 2 electrodes and vice versa. It is known from the anatomy that the heart is in left-front location within thoracic cavity. The distance from the heart to the line joining 2 electrodes of first lead $\left(E_{1}-E_{1}{ }^{\prime}\right)$ is the shortest (see Fig. 3), while that from the heart to the line joining 2 electrodes of 4 lead $\mathrm{E}_{4}-\mathrm{E}_{4}$ ' (or 5 lead $\mathrm{E}_{5}-\mathrm{E}_{5}{ }^{\prime}$ ) is the longest. Thus, it can be deduced that the amplitude of the $\mathrm{O}$ wave caused by ventricle components (LV and $\mathrm{RV})$ on first lead $\left(\mathrm{E}_{1}-\mathrm{E}_{1}{ }^{\prime}\right)$ is the biggest, while that on 4 lead $\mathrm{E}_{4}-\mathrm{E}_{4}$ ' (or 5 lead $\mathrm{E}_{5}-\mathrm{E}_{5}^{\prime}$ ) is the smallest. This deduction is in accordance with the experiment data in Table 1 and the waveform graph in Figure 3 . This indicates that the above analysis on the formation mechanism of the $\mathrm{O}$ wave in thoracic impedance graph is confirmed by the experiment results.

\section{Relation between the $\mathrm{O}$ waves of PL and PR and the hemodynamic change in $\mathrm{LV}$}

The myocardial contractility is stronger in condition of the normal cardiac function, the stroke volume and ejection fraction are bigger, and the amplitudes of the $\mathrm{C}$ waves of the PL and PR are bigger. And the blood within the LV is less in the initial diastolic stage, and the pressure in LV is lower. The recirculation resistance is smaller in the process that the blood flows from the pulmonary vein to $\mathrm{LV}$, the blood can be fleetly entered to $\mathrm{LV}$, and the blood volume in $\mathrm{LV}$ increases quickly [20]. The impedance change of $\mathrm{LV}$ is bigger in this time, and the bigger $\mathrm{O}$ wave appears in the LV. Inversely, the volume change in the pulmonary vein is smaller in this time, and its impedance change is also smaller. Thus in condition of the normal cardiac function, the smaller $\mathrm{O}$ wave appears only in the PL and PR, and the $\mathrm{O} / \mathrm{C}$ ratio of the PL and $\mathrm{PR}$ are smaller.

But in condition of the cardiac insufficiency, the myocardial contractility is weaker, the stroke volume and ejection fraction decrease, and the $\mathrm{C}$ waves of the PL and PR are smaller. The residual blood in LV is more in the initial diastolic stage and the pressure in the ventricle is higher. The recirculation resistance of the blood is bigger, and the speed that the blood is entering to the LV is slower [11]. Since the pulmonary vein needs to accept the blood which is not accepted by LV and the volume change of the pulmonary vein is bigger in this time [12], the bigger $\mathrm{O}$ waves appear often in the PL and PR and the $\mathrm{O} / \mathrm{C}$ ratio is increased.

\section{Conclusions}

The $\mathrm{O}$ wave in thoracic impedance graph is formed due to the superposition of the $O$ waves of the vascular and ventricular impedance change components. The formation mechanism of the normal and abnormal $\mathrm{O}$ waves in thoracic impedance graph is different, and they correspond to the different hemodynamic change in LV, respectively. In condition of the normal cardiac function, the $\mathrm{O}$ wave of ventricle components is of main role, and the $\mathrm{O} / \mathrm{C}$ ratio of the $\mathrm{PL}$ and $\mathrm{PR}$ is smaller. In condition of cardiac insufficiency, if the $\mathrm{O}$ waves of the vascular components are bigger than those of ventricle components, the $\mathrm{O}$ waves of the vascular components play the main role and the $\mathrm{O} / \mathrm{C}$ ratio of the PL and PR is bigger.

\section{Acknowledgements}

Authors are thankful to Professor Liu Han-Ching of Nanchang University (China) for his kind guidance and help in this study.

Conflict of interest: none declared 


\section{References}

1. Kubicek WG, Karnegis JN, Patterson RP, Witeose DA, Mattson RH. Development and evaluation of impedance cardiac output system. Aerospace Med, 1966; 37: 1208-1212.

2. Sramek BB, Rose DM, Miyamoto A. Strove volume equation with a linear base impedance model and its accuracy, as compared to thermodilution and magnetic flowmeter techniques in humans and animals. Proceeding of 6th ICEBI, Zadar, Yugoslavia, 1983; 38-41.

3. Bernsten DP, Lemmens HJM. Stroke volume equation for impedance cardiography. Med Biol Eng Comput, 2005; 43: 443-450.

4. Kieback AG, Borges AC, Schink T, Baumann G, Laule M. Impedance cardiography versus invasive measurements of stroke volume index in patients with chronic heart failure. Int J Cardiol, 2010; 143: 211-213.

5. Babbs CF. Anterior-posterior impedance cardiography: A new approach to accurate, non-invasive monitoring of cardiac function. Cardiovasc Eng, 2010; 10: 52-65.

6. Cybulski G, Strasz A, Niewiadomski W et al. Impedance cardiography: Recent adivancement. Cardiol J, 2012; 19: 550-556.

7. Van der Kleij, Koolen BB, Newhall DA et al. Clinical evaluation of a new tracheal impedance cardiography method. Anaesthesia, 2012; 67: 729-733.

8. Gu Ju-kang, Deng Kai-bai. Clinical cardiac function. He fei, China: Science and Technique Publishing Company In An Hui, 1992; 201-202.

9. Jiirverud K, Ollmar S, Brodin LA. Analysis of the O-wave in acute right ventricular apex impedance measurements with a standard pacing lead in animals. Med Biol Eng Comput, 2002; 40: 512-519.
10. Gielerak G, Piotrowicz E, Krzesiński P, Kowal J, Grzęda M, Piotrowicz R. The effects of cardiac rehabilitation on haemodynamic parameters measured by impedance cardiography in patients with heart failure. Kardiol Pol, 2011; 69: 309-317.

11. Guo-Wei Chen, Zong-E Cheng. Modern cardiology [in Chinese]. Science And Technique Publishing Company In Hu Nan, Chang sha, China 2002; 242-246.

12. Xia Hong-Qi, HLiu Guo-Quan. Pragmatic cardiac function [in Chinese]. Medicine Science And Technique Publishing Company of China, Bei Jing, China 1993; 100-101.

13. Patterson RP, Kubicek WG, Witsoe DA, From AHL. Studies on the effect of controlled volume change on the thoracic electrical impedance. Med Biol Eng Comput, 1978; 16: 531-536.

14. Baker LE, Mistry GD. Assessment of cardiac function by electrical impedance. Proceeding of 5th ICEBI., Tokyo, Japan, 1981; 7-10.

15. Wang L, Patterson R. Multiple sources of the impedance cardiogram based 3-D finite difference human thorax models. IEEE. Trans Biomed Eng, 1995; 42: 141-149.

16. Wtorek J. Relation between component of impedance cardiogram analyzed by means of finite element model and sensitivity theorem. Ann Biomed Eng, 2000; 28: 1352-1361.

17. Kuang Ming-Xing, Xiao Qiu-Jin, Cui Chao-Ying, Kuang Nan-Zhen, Hong Wen-Qin. Mechanism of the formation for thoracic impedance change. Ann Biomed Eng, 2010; 38: 1007-1016.

18. Kuang Ming-Xing, Xiao Qiu-Jin, Kuang Nan-Zhen, Cui Chao-Ying, Hu Ai-Rong. Studies on separating the impedance change components of blood vessels and ventricles in thorax from mixed impedance signals on chest surface. Med Phys, 2011, 38: 3270-3278.

19. Wangsness RK. Electromagnetic fields. $2^{\text {nd }}$ Ed. John Wiley \& Sons, New York 1986; 110-111.

20. Yao Tai. Physiology. $6^{\text {th }}$ Ed. People Health Publishing Company, Bei Jing, China 2004; 95-97. 